\title{
Formação de Professores que Ensinam Matemática: um olhar sobre as redes sociais e intelectuais do BOLEMA
}

\author{
Mathematics Teachers' Training: a look at BOLEMA's social and \\ intellectual networks
}

\author{
Bruna Larissa Cecco* \\ Luci T. M. dos Santos Bernardi** \\ Nadir Castilho Delizoicov ${ }^{* * *}$
}

\begin{abstract}
Resumo
Nosso trabalho se insere no campo da Formação de Professores que ensinam Matemática, tendo como proposta analisar a rede social e intelectual dos artigos que tratam sobre o tema, publicados no periódico BOLEMA (1985-2015). Tem aporte teórico na epistemologia fleckiana, considerando que o conhecimento é produzido coletivamente, de forma que os pesquisadores ao compartilharem um problema, referencial teórico e práticas comuns formam um coletivo de pensamento. A pesquisa que dá origem ao texto é quali e quantitativa, desenvolvida a partir da metodologia de Análise de Redes Sociais (ARS) e com o auxílio do software Gephi que forneceu estatísticas para a análise. Apoiada nas categorias fleckianas, a análise nos permite inferir que: a produção do conhecimento disponibilizada no periódico está fortemente vinculada à pós-graduação; a maioria dos artigos é oriunda de instituições da região Sudeste; a rede de coautoria que emerge tem baixa densidade, o que implica em pouca representatividade perante as relações compartilhadas; a rede intelectual concentra-se em três clusters: a Formação Inicial; a Formação Continuada e a Formação Contínua e Desenvolvimento Profissional, as quais apresentam circulação intra e intercoletiva de ideias que possibilitam emergir novas categorias, tratando de questões mais específicas.
\end{abstract}

Palavras-chave: Formação de Professores que Ensinam Matemática. BOLEMA. Análise de Redes Sociais. Circulação Intra e Intercoletiva de Ideias. Fleck.

\begin{abstract}
Our paper is part of the field of Mathematics Teacher's Training, with the purpose of analyzing the social and intellectual network of the articles that approaches the subject, published in the BOLEMA periodic (1985-2015).

\footnotetext{
* Mestra em Educação pela Universidade Comunitária da Região de Chapecó (Unochapecó). Professora de Matemática dos anos finais do Ensino Fundamental, Nonoai, Rio Grande do Sul, Brasil. Endereço para correspondência: Rua Pedro Roso, 344, Centro, CEP 99600-000, Nonoai, Rio Grande do Sul, Brasil. E-mail: brunacecco@unochapeco.edu.br

** Doutora em Educação Científica e Tecnológica pela Universidade Federal de Santa Catarina (UFSC). Professora titular do curso de Matemática e do Programa de Pós-graduação em Educação da Universidade Comunitária da Região de Chapecó (Unochapecó), Chapecó, Santa Catarina, Brasil. Endereço para correspondência: Av. Senador Atílio Fontana, 591E, Efapi, CEP 89809-000, Chapecó, Santa Catarina, Brasil. Email: lucib@unochapeco.edu.br

*** Doutora em Educação pela Universidade Federal de Santa Catarina (UFSC). Professora do Programa de Pósgraduação em Educação da Universidade Comunitária da Região de Chapecó (Unochapecó), Chapecó, Santa Catarina, Brasil, e professora colaboradora do Programa de Pós-graduação em Educação Científica e Tecnológica da Universidade Federal de Santa Catarina (UFSC), Florianópolis, Santa Catarina, Brasil. Endereço para correspondência: Av. Senador Atílio Fontana, 591E, Efapi, CEP 89809-000, Chapecó, Santa Catarina, Brasil. E-mail: ridanc.nadir@gmail.com
} 
This study has a theoretical contribution of Fleck's epistemology, considering that knowledge is produced collectively, so that researchers share a problem, theoretical framework and common practices form a collective of thought. The research that gives origin to this text is qualitative and quantitative, developed from the Social Network Analisys (SNA) methodology with the help of the Gephi software, which provided statistics for the analysis. Based on the Fleckian categories, the analysis allows us to infer that: the production of the knowledge available in the periodic is strongly linked to the postgraduate level; most of the articles come from institutions in the Southeast region; the co-authoring network that emerges has low density, which implies in little representativeness before the shared relations; the intellectual network is concentrated in three clusters: the Initial Education; Continuing Education, and Continuous Education and Professional Development, which presents intra and inter collective circulation of ideas that allow the arising of new categories, addressing more specific issues.

Keywords: Mathematics Teacher's Training. Bolema. Social Network Analysis. Intra and Inter Collective Circulation of Ideas. Fleck.

\section{Introdução}

Este trabalho é oriundo de uma pesquisa de mestrado (CECCO, 2016) que teve por objetivo compreender a configuração do campo da Formação de Professores que ensinam Matemática - FPEM$^{1}$ na dinâmica de publicação e socialização de artigos relacionados ao tema, no período de 1985 a 2015, no BOLEMA - Boletim de Educação Matemática (online ${ }^{2}$ ), periódico vinculado à Universidade Estadual de São Paulo - UNESP, que discute questões da área da Educação Matemática ou afins.

O periódico foi criado em 1985 e surgiu do esforço e engajamento de um coletivo de pesquisadores que se propunha a discutir questões da Educação Matemática no país, buscando a melhoria do ensino de Matemática nas escolas, onde "o esforço, a contribuição de cada um, presente ou ausente, e, a união de todos em torno de algo que verdadeiramente acreditam, fizeram florescer o BOLEMA - Boletim de Educação Matemática” (DANTE, 1985, p. 1).

Ao longo dos anos, o boletim foi se repaginando e, se compararmos a primeira com as últimas edições, observaremos mudanças no design, tipografia, formatação, estrutura e organização, além do processo de internacionalização pelo qual o periódico passou, a partir de 2008, e do reconhecimento como Qualis A1 nas áreas de Educação e de Ensino, na avaliação de 2014 da Coordenação de Aperfeiçoamento de Pessoal de Nível Superior - CAPES.

\footnotetext{
${ }^{1}$ A nomenclatura Formação de Professores que ensinam Matemática segue os pressupostos do Grupo de Trabalho (GT) 07, com esse mesmo nome, da Sociedade Brasileira de Educação Matemática - SBEM, que estuda a formação de professores de Matemática e de Pedagogia, considerando a atividade nos anos iniciais da Educação Básica. Usaremos a sigla FPEM.

${ }^{2}$ Trabalhamos a partir das edições online do BOLEMA, sendo que todas as edições publicadas (impressas) estão digitalizadas.
} 
Atualmente, o periódico apresenta publicação quadrimestral, além de uma edição temática anual. Ao longo de suas três décadas de existência, apresentou diversas edições especiais relativas a temáticas importantes para a Educação Matemática.

Diante da envergadura e representatividade do periódico para a área da Educação Matemática é que nos propomos a analisar a rede social e intelectual dos artigos que tratam do tema da FPEM publicados em 31 anos do BOLEMA.

Para a escolha dos artigos, trabalhamos com a seleção de Passos (2009) até 2007, e, a partir desse ano, selecionamos os artigos usando critérios semelhantes aos da autora. Inicialmente, buscamos os artigos publicados que continham palavras-chave que remetessem ao tema formação do professor. Na sequência, detivemo-nos nos artigos que contivessem títulos com essas palavras; e, por último, realizamos a leitura dos resumos para identificar os trabalhos que tratavam a respeito da Formação de Professores. Quando ficávamos em dúvida se o artigo era ou não relacionado ao tema, realizávamos a leitura na íntegra.

Após esses procedimentos, elencamos uma amostra de 107 artigos, considerando o período de 2008 a 2015 que, somados com os $27^{3}$ selecionados por Passos (2009), constituem nosso corpus relativo ao período de 1985 - 2015, com um total de 134 artigos sobre FPEM publicados no periódico BOLEMA, que representam aproximadamente 22,5\% do total dos 596 artigos publicados no periódico.

\section{Formação de Professores que ensinam Matemática: um campo de estudo}

A Formação de Professores é um importante campo de pesquisa da educação brasileira e, como explicita Marli André, apoiada em Marcelo Garcia (1999, p. 24-26, apud ANDRÉ, 2010, p. 175), configura-se num campo autônomo de estudos, haja vista a existência de um objeto próprio de estudo, metodologia específica, comunidade de cientistas com um código de comunicação próprio, integração dos participantes no desenvolvimento da pesquisa e reconhecimento da Formação de Professores como um elemento fundamental na qualidade educativa.

A pesquisa em torno do tema vem crescendo, e trabalhos na perspectiva do estado da arte (GATTI; BARRETO; ANDRÉ, 2011; ANDRÉ, 2010) buscam analisar essas produções. Diniz-Pereira (2013, p. 152) também evidencia o desenvolvimento e a consolidação da

\footnotetext{
${ }^{3}$ Os 27 artigos (1985 - 2007) foram selecionados por Passos (2009) a partir das seções: Artigos, Comunicações e Seção Especial apresentadas no periódico BOLEMA, enquanto que, em nossa coleta de dados (2008 - 2015), buscamos apenas na seção Artigos.
} 
temática em nível internacional, caracterizando-a como "um campo de lutas e interesses em que relações de força e de poder definem as principais temáticas e metodologias de pesquisa, assim como as mudanças sofridas por ele ao longo dos anos".

Na área da Educação Matemática, os estudos em relação à formação do professor que ensina Matemática são crescentes e foram categorizados nos trabalhos de Fiorentini (1994), Fiorentini et al. (2002), Melo (2006) e Passos et al. (2006), evidenciando a existência e a importância do tema.

A FPEM emerge, nas discussões da área, na década de 1990 (FIORENTINI, 1994; BRASIL, 1997), voltando exclusivamente o olhar sobre a formação do professor de Matemática. Fazendo uma breve comparação acerca dos estudos desenvolvidos por Fiorentini (1994) e Melo (2006), os quais distam duas décadas, vemos um movimento de transformação na produção de pesquisas do campo. Primeiramente, em relação à nomenclatura usada, de Formação de Professores de Matemática (FPM) para Formação de Professores que ensinam Matemática (FPEM), incluindo os professores dos anos iniciais. Além disso, a mudança na Formação Continuada, antes concebida a partir de cursos de treinamento e de projetos de atualização desenvolvidos na escola, como salientado por Fiorentini (1994), enquanto que Melo (2006) já nos apresenta a discussão da prática e formação docente em contextos socioculturais e as pesquisas sobre percepções dos professores, além do termo Formação Contínua.

Ainda, entendendo o processo de constituição da FPEM na área da Educação Matemática, destacamos o mapeamento da pesquisa acadêmica brasileira sobre o professor que ensina matemática, idealizado pelo GEPFPM (Grupo de Estudos e Pesquisas sobre Formação de Professores que Ensinam Matemática) que coloca em tela os estudos realizados no período de 2001 a 2012 acerca do professor que ensina Matemática ${ }^{4}$. De acordo com Fiorentini et al. (2016), a formação do professor é mais um dos focos dos estudos em relação ao Professor que Ensina Matemática. Assim, nominado como campo de estudo Professor que Ensina Matemática (PEM) e seus diferentes contextos, "no qual se destacam, como contextos ou dimensões centrais de estudo do professor, a formação inicial e continuada do PEM e outros contextos e aspectos relativos ao PEM” (FIORENTINI et al., 2016, p. 27).

A aprendizagem docente, o desenvolvimento profissional, as concepções, as crenças, as atitudes, as representações, os saberes, as competências, a identidade e a profissionalidade

\footnotetext{
${ }^{4}$ Apesar de o mapeamento não ser usado como subsídio no artigo, por ter sido publicado no final de 2016 , consideramos importante colocá-lo em tela, diante da sua relevância para o campo, através de uma pesquisa em âmbito nacional e com discussões recentes (2001-2012), contribuindo com o nosso trabalho. Disponível em: <https://www.fe.unicamp.br/pf-fe/pf/subportais/biblioteca/fev-2017/e-book-mapeamento-pesquisa-pem.pdf〉.
} 
docente, as condições, as características e o desempenho docentes, entre outros aspectos, são considerados por Fiorentini et al. (2016) como subcampos de estudo que permeiam a formação inicial, continuada e contínua e os outros contextos relacionados ao professor que ensina matemática.

A partir dos estudos, é importante destacar que a Formação de Professores de Matemática busca constituir uma identidade própria na Educação Matemática, com um olhar minucioso sobre a especificidade da formação para atuação na área, com referenciais teóricos próprios e passando por transformações no decorrer dos anos.

Assim, sob o referencial fleckiano, podemos dizer que a formação do professor passou por distintos estilos de pensamento, uma vez que essa categoria comporta teorias e práticas. Um estilo de pensamento é o que une os pesquisadores de um mesmo grupo, formando o que Fleck (2010) denomina de coletivo de pensamento. As transformações vão ocorrendo por força da circulação intra e intercoletiva de ideias, ou seja, circulação de ideias dentro do próprio coletivo ou entre coletivos distintos.

\section{Caminho metodológico da pesquisa}

O conhecimento é algo vivo e dinâmico, produzido coletivamente por pesquisadores que se debruçam a estudar um mesmo tema e que, quando compartilham um problema, referencial teórico e práticas comuns, formam um coletivo de pensamento (FLECK, 2010).

Os grupos de pesquisadores constituem redes de colaboração científica, que são formadas nas relações estabelecidas pela ciência. As redes de colaboração entre os pesquisadores na produção de artigos se efetivam na coautoria, entendendo-se que coautor é aquele que produz algo com outrem.

A produção coletiva do conhecimento científico pode acontecer entre pesquisadores de um mesmo grupo, ou de grupos diferentes; entre pesquisadores de uma mesma instituição ou distintas, ou até mesmo, entre instituições de um mesmo país ou de países diferentes. Existem fatores que influenciam a formação das redes de colaboração científica, como os cognitivos, sociais ou econômicos, ou, ainda, questões de financiamento, ou de algum material/equipamento que precisa ser compartilhado (BALANCIERI et al., 2005).

Compreender a disposição da rede pela coautoria entre pesquisadores significa entender a dinâmica de produção do conhecimento, identificando as possíveis relações que influenciam essa produção e o fortalecimento da área. 
Uma rede de coautoria é uma rede na qual os nós são os professores / pesquisadores, e há conexão entre eles sempre que partilham a autoria de um artigo. A visualização da rede, na forma de grafos, é considerada pelos autores da área, mais intuitiva do que a visualização na forma de matrizes, embora os dados coletados sejam, normalmente, apresentados dessa forma (SILVA et al., 2006, p. 78).

As redes são configuradas a partir das inúmeras conexões (arestas) entre os atores (nós ou vértices), representadas por grafos. Para o estudo e análise das redes, utilizamos a Análise de Redes Sociais (ARS ou SNA do inglês Social Network Analysis), que é uma metodologia qualitativa de pesquisa com conceitos $^{5}$ e terminologias próprias, como: nó, aresta, ator, elos relacionais, grau nodal, centralidade, densidade, clusters, entre outros.

Neste trabalho, os nós representam os pesquisadores (ou as palavras-chave) dos artigos, e as arestas as relações estabelecidas no processo de produção do conhecimento, evidenciando as produções realizadas de forma conjunta, através da coautoria de artigos ou, ainda, os temas e interesses compartilhados pelos pesquisadores do campo da FPEM.

Os grafos apresentam diversas medidas. A ordem de um grafo representa o número de vértices de um grafo, o tamanho é dado pelo número de arestas existentes entre os vértices de um grafo e o grau de um vértice ou degree diz respeito ao número de conexões que um vértice possui. Isso significa que, quanto mais arestas estão ligadas a um vértice, maior é seu grau e a sua significância no grafo.

A densidade é dada pela relação entre a ordem e o tamanho do grafo e é utilizada para avaliar a conectividade entre os grafos, que varia entre 0 (grafos totalmente desconectados) e 1 (grafos totalmente conectados). De acordo com Lima (2009, p. 33) a densidade representa um importante indicador de conectividade da rede, aliás, "quanto maior for a conectividade de uma rede, maior é a sua atividade interna, em termos de número de parcerias ou de trabalhos publicados em coautoria, no contexto das redes de coautoria.” (LIMA, 2009, p. 33).

$\mathrm{Na}$ estrutura de redes conectadas podem existir cutpoints, que são pontos (nós) que têm a função de ligar blocos da rede e, quando removidos, podem desconectar os grafos.

O cutpoint é o elo entre vários pesquisadores e grupos de pesquisadores; se ele for excluído da rede, vários membros da rede serão desconectados, [...], culminando em uma rede (mais) desconectada; por isso, esses atores possuem uma importância ímpar na conectividade da rede. (LIMA, 2009, p. 32, grifo do autor)

Assim, o cutpoint é um nó importante na rede por ter a função de conectar dois diferentes blocos.

Na Figura 1, o vértice $\mathrm{G}$ é um cutpoint que tem a função de ligar dois blocos de pesquisadores na produção do conhecimento. Um é o bloco formado pelos pesquisadores A,

\footnotetext{
5 Apesar da importância da metodologia para o estudo, destacamos apenas os conceitos essenciais para o entendimento do trabalho. Para maior detalhamento dos conceitos, indicamos ver Cecco (2016).
} 
B, C, D, E, F e H, e o outro é formado pelos pesquisadores I, J, K e L. Assim, o pesquisador G é o único que está nos dois grupos, caracterizando-se como um elo entre os grupos.

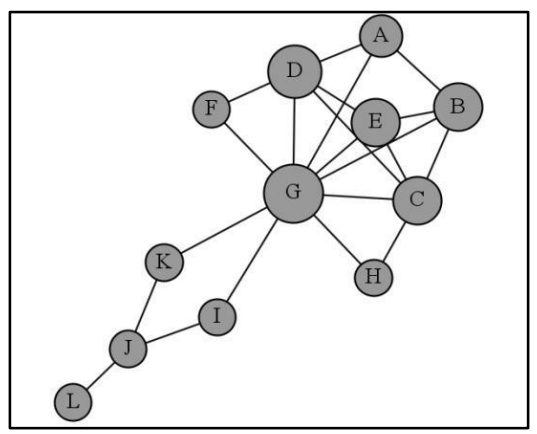

Figura 1 - Grafo com cutpoint Fonte: Elaborado pela autora

Outra medida importante na teoria de grafos é a formação de agrupamentos ou de clusters (em inglês). No caso da rede de pesquisadores, a formação de clusters acontecerá a partir das relações existentes entre os pesquisadores que tenham atividades semelhantes ou que as desenvolvam conjuntamente. Isso poderá acontecer no estudo de uma mesma temática, de uma teoria, ou de uma metodologia dentro das pesquisas do tema em estudo ou, ainda, no trabalho colaborativo existente em um mesmo grupo ou universidade, por exemplo. "Na rede de coautoria, um cluster é formado por um agrupamento ou subconjunto de pesquisadores que se relacionam, dentro do grafo." (LIMA, 2009, p. 32).

Na Figura 1, os dois grupos de pesquisadores que estão conectados através do vértice $\mathrm{G}$ podem ser considerados clusters, pois formam um subgrupo (dentro do grafo) de pesquisadores que se relacionam através da coautoria. Podemos dizer que esses clusters formados pelos pesquisadores produzem conhecimento de forma que os nós A, B, C, D, E, F e $\mathrm{H}$ formam um coletivo com ideias diferentes das do coletivo formado pelos nós $\mathrm{K}, \mathrm{I}, \mathrm{J}$ e L. Em cada um desses coletivos existe circulação de ideias sobre um tema. Podemos afirmar, ainda, que o cutpoint $\mathrm{G}$ é o nó responsável por fazer o intercâmbio dos conhecimentos de um cluster para outro, promovendo, assim, a circulação de ideias entre esses clusters.

Quando existe o intercâmbio de ideias de um grupo para outro, Fleck (2010) se refere à circulação intercoletiva de ideias, advertindo que, nesses casos, pode provocar alterações ou mudança de ideias durante a migração de um grupo para outro, pois "a simples comunicação de um saber [...] nunca acontece sem a transformação, mas sempre com uma modificação". (FLECK, 2010, p. 162-163).

As medidas de centralidade são indicativos importantes de um vértice em relação ao grafo. Para Gabardo (2015), a centralidade de grau é dada em relação ao número de vértices do grafo que estão conectados a um vértice em particular e a centralidade de proximidade 
avalia o quão próximo aos demais vértices da rede um determinado vértice está. "Uma alta proximidade significa que um determinado pesquisador está estruturalmente bem posicionado na rede em relação aos demais pesquisadores que fazem parte dessa mesma rede" (LIMA, 2009, p. 34).

A centralidade de intermediação é medida levando-se em conta quantas vezes um vértice faz parte do menor caminho entre um par de vértices qualquer do sistema. De acordo com Lima (2009, p. 34), a centralidade de intermediação avalia o quanto um determinado pesquisador conecta outros pesquisadores que não se relacionam diretamente. Uma alta intermediação significa que um pesquisador está estruturalmente bem posicionado, conectando pesquisadores que não se conectam diretamente.

As métricas fornecidas por grafos são essenciais para compreender a estrutura e, principalmente, para realizar análises do comportamento da rede. Nesse sentido, a pesquisa que subsidia este texto é de cunho quali e quantitativo, visto que a abordagem qualitativa fornecida pela metodologia da ARS é potencializada com as medidas quantitativas indicadas pelo próprio software em relação à rede, fornecendo melhores explicações acerca do problema em estudo.

Apesar das controvérsias em relação às duas abordagens, Minayo (2013) enfatiza que as abordagens qualiquantitativas da realidade social têm uma diferença de natureza e não de escala hierárquica, visto que há uma oposição complementar entre elas, "que, quando bem trabalhada teórica e praticamente, produz riqueza de informações, aprofundamento e maior fidedignidade interpretativa" (MINAYO, 2013, p. 22).

Nesse tipo de estudo, a importância de aliar as abordagens qualitativa e quantitativa é salientada por Silva et al. (2006, p.79), quando afirmam que "autores estudados tomam o cuidado de salientar que o uso da ARS e de métodos estatísticos não eliminam a necessidade de uma análise qualitativa aprofundada". Assim, realizamos a seleção dos artigos que tratam da FPEM no periódico BOLEMA pelas palavras-chave, ficando, como já explicitado, com um total de 134 artigos publicados no período de 1985 - 2015. Com os artigos selecionados, iniciamos o processo de organização tabular para posterior construção das redes com informações relevantes, como: quantidade de autores, relação entre os autores, titulação dos autores, localização geográfica do artigo, processo de construção do artigo, palavras-chave, resumo, referencial teórico, entre outras.

\section{Análise da estrutura social dos artigos}


Após o levantamento inicial, identificamos que, dos 134 artigos selecionados, 33 são de origem internacional. Cerca de $40 \%$ dos artigos nacionais resultam de dissertações ou teses $^{6}$, evidenciando a importância da pesquisa desenvolvida nos cursos de pós-graduação. Há uma grande concentração de artigos oriundos de instituições da região Sudeste (79 artigos), seguida pela região Sul (16 artigos), Centro-oeste (seis artigos) e Nordeste (quatro artigos) em menor número; nenhum dos artigos selecionados é oriundo da região Norte.

As instituições brasileiras com maior número de publicações sobre a FPEM no BOLEMA são: UNESP, com 24 artigos publicados; seguida da UNICAMP, com nove trabalhos; UFSCAR, com oito; PUC - SP, com seis trabalhos; USP, com cinco trabalhos; e UFRJ, com quatro trabalhos. Destaca-se que todas essas instituições estão localizadas na região Sudeste.

Identificamos a origem das pesquisas no resumo ou no texto completo e, para os artigos que não tinham explícitas essas informações, consultamos o currículo lattes dos pesquisadores para entender a constituição das pesquisas. Assim, um artigo oriundo de uma tese ou dissertação, geralmente, possuía como autores o orientador e o orientando. Mesmo que o orientando trabalhasse em outra instituição, consideramos como origem a instituição na qual o trabalho de mestrado ou doutorado foi desenvolvido.

Além da instituição, identificamos os pesquisadores/autores que publicaram no BOLEMA. Os 134 artigos foram escritos por 232 autores diferentes, quantidade de autores é superior ao número de trabalhos, indicando a coautoria.

A rede ${ }^{7}$ (Figura 2) foi construída no software Gephi com os 232 autores identificados nos 134 artigos selecionados no periódico BOLEMA. Os nós representam os autores e as arestas as ligações entre os autores, pela coautoria. Quanto às escolhas para representação da rede, aperfeiçoamos a apresentação dos grafos a partir do tamanho e das cores dos nós, e, optamos por utilizar o algoritmo Fruchterman Reingold, que faz uma distribuição circular dos vértices, colocando os elementos com maior centralidade no centro, produzindo, assim, um grafo de mais fácil compreensão.

\footnotetext{
${ }^{6}$ Dos 101 artigos nacionais, quarenta foram escritos por apenas uma pessoa, caracterizando a autoria, enquanto que 61 artigos possuem dois ou mais autores, caracterizando a coautoria. Nesses artigos (61) com dois ou mais autores, dezoito deles foram oriundos de processos de dissertação de mestrado e treze resultam de teses de doutorado, indicando a presença da coautoria nos processos da pós-graduação brasileira, e a importância da mesma para o fortalecimento da produção do conhecimento. Encontramos seis artigos com autoria única que também se originaram de mestrados ou doutorados. Além disso, indicamos a existência de estudos oriundos da graduação (3) e do pós-doutorado.

${ }_{7}$ Os artigos de autoria própria estão representados por um nó (normal) sem nenhuma ligação. Os autores que publicaram um trabalho sozinho e como coautores em outros trabalhos, representamos por um nó maior (tamanho 20) e de cor azul, e os autores que publicaram dois artigos sozinhos foram representados por um nó maior (tamanho 20) e de cor verde.
} 


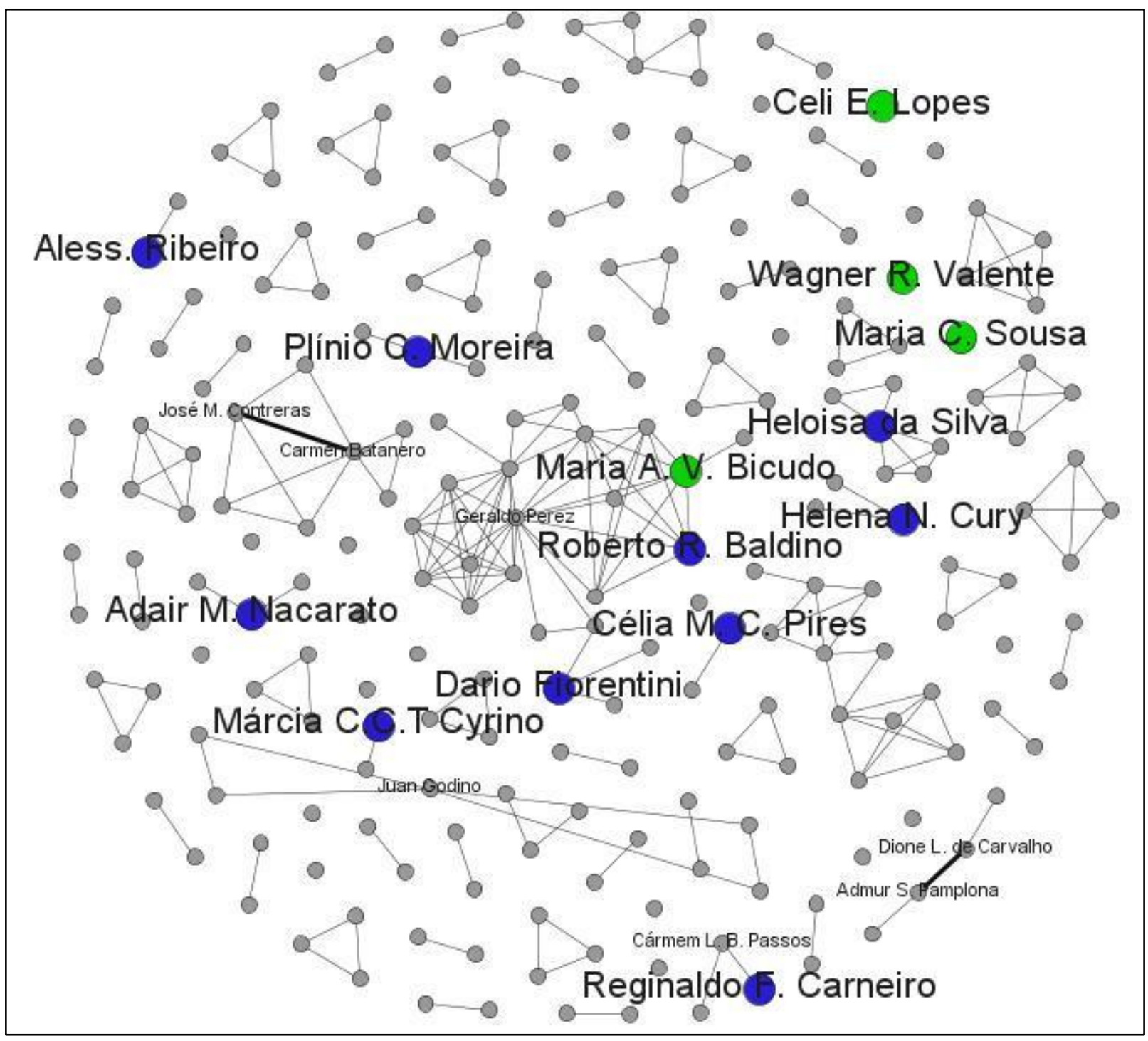

Figura 2 - Rede dos autores dos 134 artigos selecionados no periódico BOLEMA Fonte: Dados da pesquisa

Dos trabalhos selecionados, encontramos artigos com um autor, dois autores, e até com oito autores. Porém, apesar da variabilidade, a maioria dos artigos analisados possui entre dois e três autores, confirmada pelas estatísticas fornecidas pelo software Gephi, explicitando que o grau médio da rede é 2,009, ou seja, em média cada vértice tem 2,009 arestas conectadas.

Analisando a rede, observamos que os autores que publicaram dois trabalhos sozinhos foram: Celi Espasandin Lopes, Wagner Rodrigues Valente, Maria do Carmo de Sousa e Maria Aparecida Viggiani Bicudo, a única que, além de publicar dois trabalhos de autoria única, também produziu dois trabalhos em coautoria.

Os nós de tamanho maior e azuis se destacam por representarem autores que publicaram um artigo de autoria única e mais artigos com seus pares. Alessandro Jacques Ribeiro, Márcia Trindade da Costa Cyrino, Célia Maria Carolino Pires e Reginaldo F. 
Carneiro publicaram um artigo de autoria própria e compartilharam com a produção de outro artigo com apenas uma pessoa. Já os autores Plínio Cavalcanti Moreira, Adair Mendes Nacarato, Helena Noronha Cury publicaram mais dois trabalhos, além do de autoria própria, cada um com um parceiro diferente. A autora Heloísa da Silva também publicou mais dois trabalhos, porém em cada um deles teve mais dois coautores. Roberto Baldino, que também produziu um artigo de autoria única, escreveu mais um trabalho com outros seis autores. $\mathrm{O}$ autor Dario Fiorentini, além de publicar um trabalho como autor único, compartilhou a autoria de mais três artigos, cada um com um autor diferente.

Outro movimento que nos chama a atenção na rede são as arestas um pouco mais espessas existentes entre alguns autores. Essas arestas indicam que esses autores publicaram duas vezes artigos em autoria conjunta, indicando que existe uma relação mais forte entre eles na produção de pesquisas. Os únicos autores brasileiros que escreveram dois trabalhos em conjunto foram Admur Severino Pamplona e Dione Lucchesi de Carvalho, com uma aresta mais espessa de ligação. Outra aresta desse tipo é identificada em artigos internacionais de autoria de Cármen Batanero e José Miguel Contreras, que foram coautores em dois trabalhos, indicando uma relação expressiva entre os autores.

Ainda, observando a rede formada pelos autores da Figura 2, alguns nós chamam a atenção na parte central da rede. É o caso do grafo representado na Figura 3 que tem destacados alguns autores fundamentais para as ligações existentes.

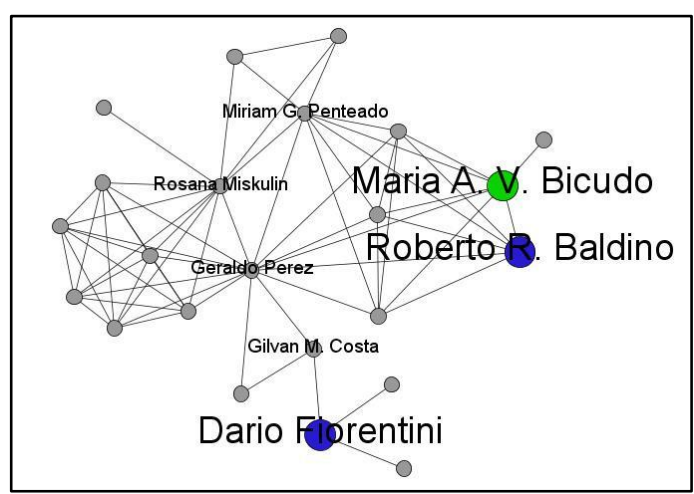

Figura 3 - Grafo com nós importantes Fonte: Dados da pesquisa

Geraldo Perez foi coautor em três trabalhos e produziu com mais quinze autores diferentes, é o nó com maior grau, com quinze arestas conectadas. Na sequência, Rosana Giaretta Sguerra Miskulin tem grau onze, atuando como coautora em três trabalhos com mais onze autores. Miriam Godoy Penteado, também em destaque na rede, é coautora de dois trabalhos, com mais nove coautores. Gilvan Machado da Costa também tem importância na rede, por ser coautor em um trabalho junto com Geraldo Perez, e em outro trabalho junto com 
Dario Fiorentini. Na sequência, Maria Aparecida Viggiani Bicudo tem grau sete, aparece como autora de dois artigos de autoria própria e é coautora de mais dois artigos com sete autores diferentes.

Outros nós em destaque na Figura 3 representam Juan Godino, Pablo Martínez, José Carrilo e Cármem Lúcia Brancaglion Passos, que foram coautores em mais de um artigo com coautores diferentes, evidenciando a diversidade e a dinâmica da pesquisa.

Quanto à centralidade de intermediação, Geraldo Perez e Gilvan Machado da Costa são os nós que possuem maior grau de centralidade de intermediação, sendo considerados como pontes, visto que conectam outros pesquisadores que não se relacionam diretamente.

Destacamos que os autores que mais publicaram artigos sobre o tema no periódico, no período analisado, foram Dario Fiorentini e Maria Aparecida Viggiani Bicudo, com quatro trabalhos, somando os de autoria própria e compartilhada. Ambos os autores, na rede em estudo, possuem pequeno número de pares escrevendo e discutindo junto com eles sobre FPEM.

Na rede formada pelos autores dos 134 artigos, a densidade é igual a 0,009, próxima a zero, indicando que o número de publicação de trabalhos em conjunto é pequeno. A densidade muito baixa indica que a rede de coautoria dos artigos publicados em um periódico não consegue ser representativa perante as relações compartilhadas. Assim, a não configuração de uma rede de coautoria em um periódico científico se dá, provavelmente, pelas relações implícitas nas políticas editoriais dos periódicos e dos próprios currículos lattes dos pesquisadores.

Como a rede de coautoria ou rede social do periódico possui pouca representatividade, propomo-nos a entender como se desenvolve a estrutura intelectual dos artigos a partir das palavras-chave apresentadas. Acreditamos que existem autores discutindo sobre a mesma temática, mas que não estão ligados pela coautoria; assim, a estrutura intelectual nos permitirá visualizar uma aproximação entre as temáticas em pauta. Lembramos, ainda, que estamos analisando um periódico Qualis A1, portanto representativo na área, por socializar as pesquisas que vêm sendo desenvolvidas e as últimas tendências do campo nas áreas nacional e internacional.

\section{Análise da estrutura intelectual dos artigos}

Após a seleção dos 134 artigos, partimos para mais uma leitura, identificando as palavras-chave por eles apresentadas, buscando subsídios nos resumos e na totalidade do 
artigo para a construção/escolha desses cinco termos. Assim, as produções com três ou quatro palavras-chave tinham seu resumo lido e, se necessário, todo o texto para buscar mais uma ou duas palavras para completar as cinco por artigo. Da mesma forma, os trabalhos com mais de cinco palavras foram lidos e os termos em excesso foram descartados.

A partir das palavras-chave elencadas, construímos a rede da Figura 4 no software Gephi com o algoritmo Fruchterman Reingold, lembrando que a rede é formada por 134 artigos, os quais possuem cinco palavras-chave, sendo que, muitas delas, são apresentadas em mais de um artigo, aumentando, assim, o grau de cada vértice.

A rede possui 292 vértices, ou seja, emergiram 292 palavras-chave dos 134 artigos, que são ligadas por 1161 arestas. Visualmente, conseguimos notar que as palavras-chave com maior destaque na rede são Formação de Professores, Educação Matemática, Licenciatura em Matemática, Ensino de Matemática e Formação Continuada de Professores, visto que o layout usado distribui os vértices igualmente no espaço disponível, minimizando o cruzamento de arestas, fornecendo simetria ao grafo.

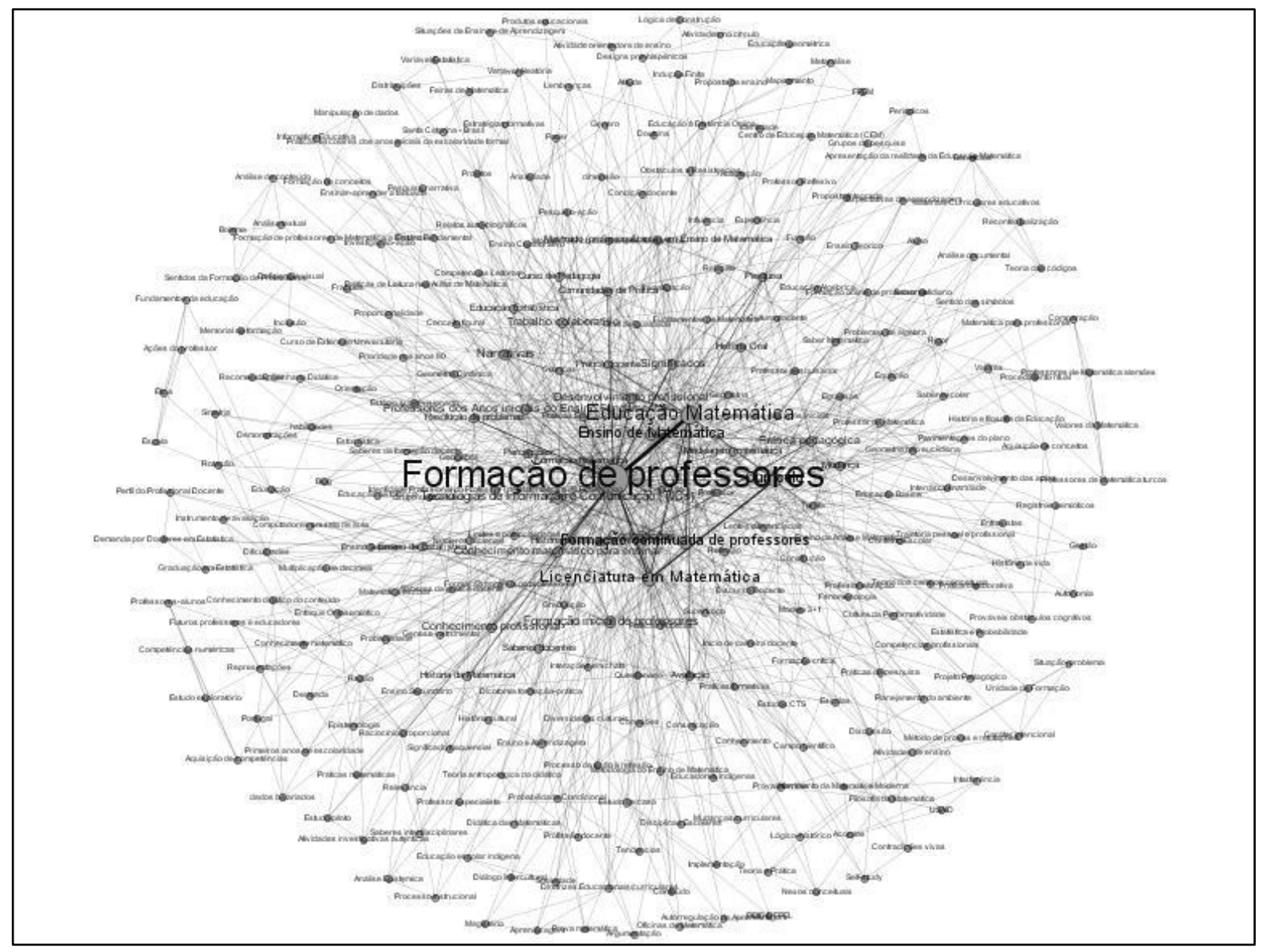

Figura 4 - Rede das palavras-chave dos 134 artigos selecionados no BOLEMA sobre FPEM Fonte: Elaborado pela autora

Pelas estatísticas fornecidas pelo software, a rede apresenta diâmetro igual a cinco e o grau médio de 7,952, ou seja, em média, cada vértice tem oito arestas. A densidade da rede é 
igual a 0,027 , considerada baixa, com pouca atividade ou termos comuns na produção dos artigos.

As palavras com maior significância são dadas pelos vértices com maior grau, indicando o número de arestas que o vértice possui. Assim, em ordem decrescente, as 12 palavras-chave que mais aparecem no conjunto dos 134 artigos são: Formação de Professores (grau $=166)$, Educação Matemática $($ grau $=79)$, Licenciatura em Matemática $($ grau $=51)$, Formação Continuada de Professores (grau $=45)$, Currículo (grau $=44)$, Ensino de Matemática (grau $=40$ ), Formação Inicial de Professores $($ grau $=37$ ), Tecnologias de Informação e Comunicação (TICs) (grau = 36), Concepções (grau = 34), Narrativas (grau = 32), Desenvolvimento Profissional (grau $=29$ ) e Prática Pedagógica (grau $=27$ ).

Fica evidente que palavras de ordem mais generalizada são apresentadas em muitos artigos, como Formação de Professores e Educação Matemática, outras bem próximas do tema, como Licenciatura, Formação Inicial e Formação Continuada de Professores, e, ainda, alguns temas mais particulares, como Currículo, TICs, Concepções, Narrativas, Desenvolvimento Profissional e Prática Pedagógica vêm ganhando destaque nas discussões da área, e se tornando inerentes ao campo.

Com a rede e a leitura dos artigos selecionados, percebemos a existência de eixos temáticos como foi apresentado por Fiorentini (1994) e Melo (2006). Não pretendemos dicotomizar os artigos, tornando-os estanques, pois entendemos que a Formação de Professores deve ser um processo de formação contínua, começando na formação inicial e se estendendo ao longo da atuação profissional do professor. Porém, entendemos que essas subdivisões estão intrincadas num campo com ampla pesquisa como a FPEM, compostas por grupos de pesquisadores tratando de diferentes temáticas que integram a área.

Assim, observando a rede da Figura 4, as estatísticas fornecidas pelo software, bem como os trabalhos desenvolvidos por Fiorentini (1994) e Melo (2006) e os resumos dos artigos selecionados no BOLEMA, identificamos que os artigos poderiam ser subdivididos em três categorias: Formação Inicial; Formação Continuada; Formação Contínua e Desenvolvimento Profissional ${ }^{8}$.

Partindo disso, construímos os clusters de cada uma dessas categorias no software Gephi. Dessa forma, a partir da Figura 4, escolhemos o nó que desejávamos obter o cluster e aplicamos na opção filtros, Rede Ego, digitamos o ID do nó de nosso interesse, com

\footnotetext{
${ }^{8}$ Para essa classificação, concordamos com Passos et al. (2006) quando afirmam que "[...] consideramos a formação docente numa perspectiva de formação contínua e de desenvolvimento profissional, pois pode ser entendida como um processo pessoal, permanente, contínuo e inconcluso que envolve múltiplas etapas e instâncias formativas" (PASSOS et al., 2006, p. 195).
} 
profundidade 1 e desmarcamos a opção consigo mesmo, pois não desejávamos que o nó aparecesse na rede, e sim com quais nós está conectado, além de escolhermos como layout a distribuição Fruchterman Reingold.

A Figura 5 representa o cluster da formação inicial, formado por 37 palavras-chave diferentes, conectadas por 85 arestas. As palavras-chave com maior grau nesse cluster são: Licenciatura em Matemática (grau = 13), TICs (grau = 10), Ensino de matemática e Currículo (ambas com grau = 9), Ensino de Estatística e Identidade do Professor (com grau 8), Concepções, Narrativas e Diretrizes Educacionais/Curriculares (com grau $=6$ ).

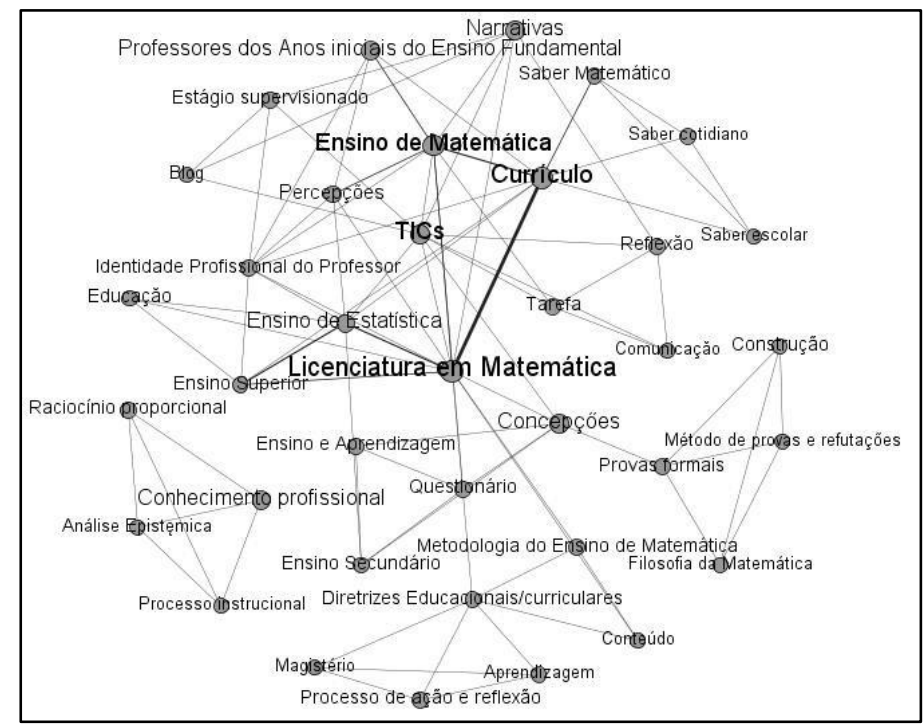

Figura 5 - Cluster: Formação Inicial Fonte: Dados da pesquisa

O cluster indica um maior número de trabalhos que tratam da Formação Inicial discutindo sobre a Licenciatura em Matemática, com as TICs como apoio na formação e na atuação do professor, preocupações em relação ao ensino da matemática na escola e aos currículos dos cursos e da educação básica. Com menor grau, mas não menos importantes, vemos as discussões voltadas ao ensino de estatística, à identidade do professor e, ainda, preocupações em relação às concepções dos professores por meio das narrativas.

$\mathrm{Na}$ Formação Inicial podemos encontrar subdivisões como as apresentadas por Melo (2006) e Fiorentini (1994). Muitos artigos fazem análises de disciplinas, cursos e programas, principalmente os cursos de Licenciatura, sendo que alguns se debruçam sobre os currículos.

Dois artigos evidenciam o uso das TICs na formação inicial, e, ainda, destacam separadamente a comunicação e a reflexão, e o uso de narrativas no estágio supervisionado. Dos trabalhos identificados, quatro deles se preocupam com o ensino de estatística nos cursos de graduação e, consequentemente, na educação escolar básica, evidenciando a importância dessa disciplina na Formação Inicial. 
Os estudos (três) sobre concepções na Formação Inicial são apresentados procurando entender as concepções de estudantes sobre as contribuições do curso de licenciatura; as matemáticas e o processo de ensino-aprendizagem; a compreensão do conceito de razão. Quanto aos estudos sobre narrativas, quatro trabalhos foram identificados e apresentam as narrativas de estudantes frente ao desenvolvimento de diversas atividades: perspectiva colaborativa vivenciada durante o estágio, produção de narrativas autobiográficas na disciplina História do Ensino da Matemática, narrativas sobre as lembranças relacionadas à Matemática durante a vida escolar e a utilização de blogs como um dos instrumentos de avaliação da disciplina de Estágio Curricular Supervisionado.

$\mathrm{Na}$ sequência, apresentamos, na Figura 6, o cluster da Formação Continuada, construído de forma análoga ao anterior.

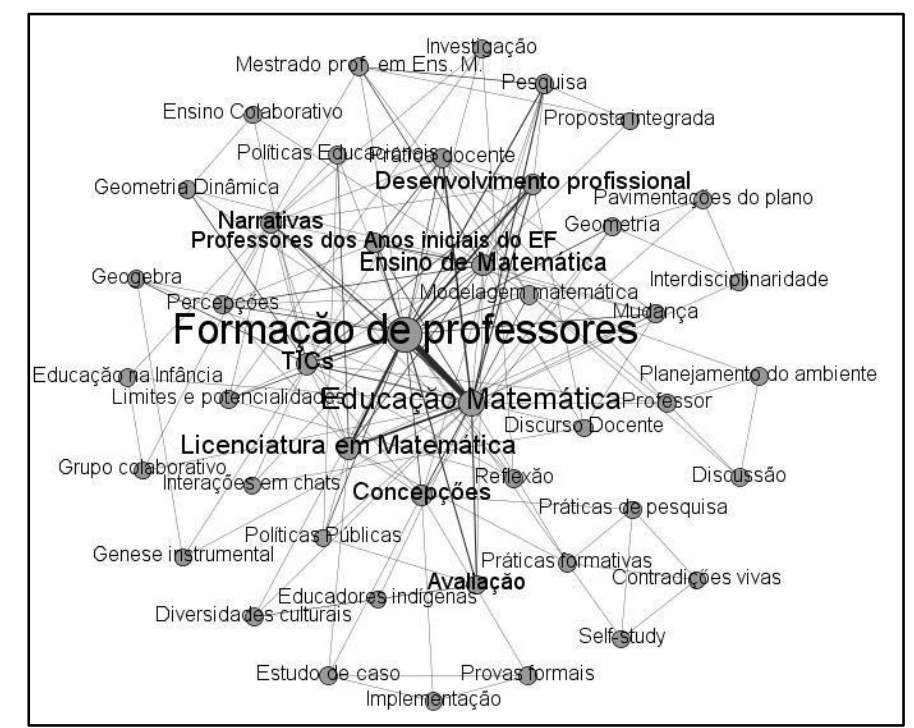

Figura 6 - Cluster: Formação Continuada Fonte: Dados da pesquisa

A rede é formada por 45 nós, ou seja, são 45 palavras-chave diferentes conectadas por 148 arestas. Ela apresenta um grau médio de 6,578 e densidade de 0,149. Quanto à centralidade de grau, as palavras-chave que mais se destacaram nos artigos da linha de Formação Continuada são: Formação de professores e Educação Matemática (com grau = 25), Ensino de matemática e TICs (com grau $=17$ ), Narrativas (grau $=13$ ), Licenciatura em Matemática $($ grau $=12)$, Concepções $($ grau $=11)$, Modelagem Matemática $($ grau = 10), Desenvolvimento Profissional e Prática Docente (com grau =9).

De acordo com a rede da Formação Continuada, os artigos publicados no BOLEMA discutem a formação continuada na perspectiva da Educação Matemática, evidenciando temas importantes como o Ensino da Matemática e o uso das tecnologias no processo de formação continuada de professores, analisando, ainda, as narrativas e as concepções de professores, 
bem como a prática docente desenvolvida por esses profissionais. Emerge, também, um foco importante nesses estudos a partir da modelagem matemática, tendência da Educação Matemática que aparece como uma possibilidade interessante no processo de ensino e aprendizagem.

Na rede ainda aparecem os termos Formação de professores, de ordem mais geral, e o Desenvolvimento Profissional, que é um dos focos da FPEM associado à formação contínua, dando a ideia de que o professor deve estar num processo constante de formação. O termo Licenciatura em Matemática também aparece na rede, com artigos discutindo sobre as políticas públicas brasileiras inerentes ao processo de formação.

O cluster referente ao tema Desenvolvimento Profissional foi construído no Gephi, usando o mesmo layout que os anteriores, e pode ser observado na Figura 7. O cluster é composto por 29 nós e 94 arestas, com um grau médio de 6,843 e uma densidade de 0,232.

As palavras-chave com maior destaque no cluster Desenvolvimento Profissional são: Formação de Professores (grau = 22), Educação Matemática e TICs (com grau = 13), Ensino de Matemática (grau = 12), Trabalho Colaborativo (grau = 10), Formação Continuada, Prática Pedagógica e Narrativas (ambas com grau = 9), Pesquisa e Educação Estatística (com grau = 7).

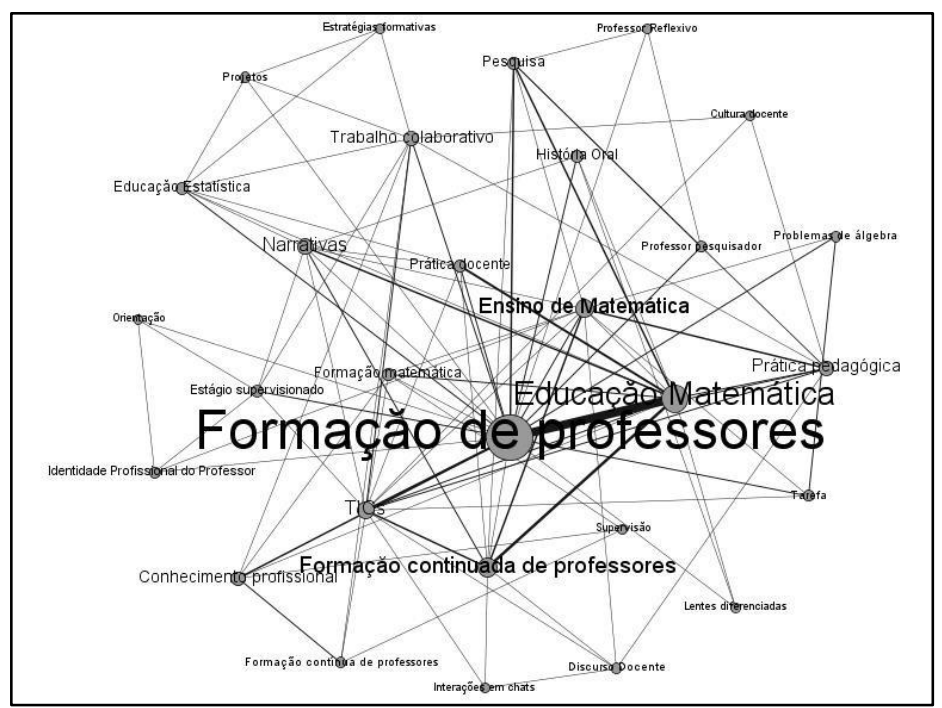

Figura 7 - Cluster: Desenvolvimento profissional Fonte: Dados pesquisados

Novamente, as palavras Formação de professores e Educação Matemática aparecem num sentido de generalização, e as tecnologias aliadas ao ensino de Matemática têm seu papel destacado. Além disso, o trabalho colaborativo ganha um viés importante no cluster, junto com as práticas pedagógicas desenvolvidas pelos professores e as narrativas como fontes de informação para a pesquisa, em que a Educação Estatística também é colocada em tela. 
Dez artigos apresentam o Desenvolvimento Profissional como uma de suas palavraschave. Evidenciamos, ainda, que o Desenvolvimento Profissional pode acontecer tanto no processo da Formação Inicial, como no processo da Formação Continuada, num movimento de continuação do processo formativo dos professores.

Analisando a rede das palavras-chave de todos os artigos, na Figura 4, e analisando cada cluster de forma isolada, fica evidente que o coletivo de pesquisadores que publicaram artigos sobre FPEM no BOLEMA divide-se em torno de três temáticas: da Formação Inicial; da Formação Continuada e da Formação Contínua e Desenvolvimento Profissional.

Apontamos que essas divisões relacionam-se entre si através da circulação intercoletiva de ideias (FLECK, 2010), que ficam explícitas na própria repetição de palavraschave nos três clusters: Tecnologias de Informação e Comunicação (TICs); o Ensino de Matemática; o Ensino ou a Educação Estatística; as Narrativas.

A partir da circulação de ideias existente nos artigos sobre FPEM, publicados no BOLEMA, é que o campo vem se constituindo e se consolidando como uma importante região de inquérito da Educação Matemática e da Educação em geral.

\section{Considerações finais sobre as redes social e intelectual do periódico BOLEMA}

A partir da estrutura social dos artigos analisados neste estudo, observamos que a rede de autoria e coautoria não tem representatividade perante as relações compartilhadas. Implicitamente, sabemos que existem pesquisadores estudando um mesmo tema, porém, por não compartilharem autoria de artigos não possuem nenhuma ligação.

O fato de a estrutura social não ser representativa não implica que o periódico não seja representativo. Pelo contrário, acreditamos que a diversidade de autores nas relações compartilhadas mostra a importância do periódico na disseminação de conhecimentos da área, nacional e internacionalmente.

Além disso, a produção do conhecimento está fortemente vinculada à pós-graduação e, principalmente, aos processos constituídos nas pesquisas de mestrado e doutorado desenvolvidas, com um número expressivo de artigos com a coautoria entre orientando e orientador (cerca de $25 \%$ do total de artigos selecionados).

Feitas as leituras, observamos que muitos artigos, apesar de não terem nenhuma proximidade pelas redes de coautoria, apresentam afinidade quanto às temáticas ou às metodologias utilizadas. É nesse movimento que identificamos a circulação intra $e$ intercoletiva de ideias nos artigos publicados sobre FPEM pelo grupo de pesquisadores. 
No decorrer do estudo e das análises, identificamos o nascimento de outras temáticas incorporadas às já existentes e reconhecidas pelos pesquisadores da área (FIORENTINI, 1994; MELO, 2006).

A primeira categoria que identificamos é o coletivo de pesquisadores que estudam o tema da FPEM, usando como metodologia a História Oral $^{9}$. Os seis trabalhos que identificamos são oriundos da UNESP (três trabalhos), UFPR, USP e UEM, quase todos vinculados ao $\mathrm{GHOEM}^{10}$, constituindo uma nova categoria, compartilhando uma mesma metodologia para estudo e que permeia as três categorias elencadas. Pelas características identificadas, possivelmente formam um coletivo de pensamento (FLECK, 2010).

A segunda categoria que nos chamou atenção refere-se aos estudos que abordam a pesquisa colaborativa (que implica parceria e trabalho conjunto) e pesquisas que têm por objeto de investigação práticas e grupos colaborativos.

Entre esses artigos, identificamos sete que indicavam como palavra-chave os termos trabalho colaborativo ou grupo colaborativo. Os artigos selecionados são oriundos de diferentes instituições: UNICAMP, UNESP, UFSCAR, e inclusive de instituições internacionais: Portugal (um trabalho) e Espanha (um trabalho).

Nos artigos oriundos de instituições brasileiras, observamos que a UNESP e a UNICAMP são as universidades que estão à frente no desenvolvimento de pesquisas na perspectiva colaborativa. Da mesma forma, evidenciamos que os pesquisadores que escreveram os artigos estão relacionados por fazerem pesquisas a partir da colaboração, formando, assim, mais um cluster, ou ainda, mais uma categoria dentro do coletivo de pesquisadores da FPEM, isso porque o uso da colaboração não se desenvolve apenas na formação inicial ou na continuada, mas, sim, na diversidade de pesquisas.

Doze artigos que se debruçam sobre o Ensino e a Educação Estatística na Formação de Professores constituem outra categoria identificada no coletivo formado pelos pesquisadores da FPEM que publicaram artigos no BOLEMA, sendo que sete deles foram publicados na Edição especial de 2011, que discutia o tema.

\footnotetext{
${ }^{9}$ A História Oral é uma metodologia de pesquisa que consiste em realizar entrevistas gravadas com pessoas que podem testemunhar sobre acontecimentos, conjunturas, instituições, modos de vida ou outros aspectos da história contemporânea. As entrevistas de história oral são tomadas como fontes para a compreensão do passado, ao lado de documentos escritos, imagens e outros tipos de registro.

${ }^{10}$ O Grupo História Oral e Educação Matemática - GHOEM - foi criado no ano de 2002. Sua intenção inicial foi reunir pesquisadores em Educação Matemática interessados na possibilidade de usar a História Oral como recurso metodológico. Atualmente, o GHOEM é um grupo multinstitucional.
} 
Outra categoria explícita em nossa análise é formada pelo grupo de pesquisadores que escreveram doze artigos sobre a utilização das Tecnologias de Informação e Comunicação (TICs) como ferramenta para o ensino de matemática e na própria Formação de Professores.

Sem a pretensão de classificar todas as categorias que permeiam os artigos, podemos dizer que os inúmeros pesquisadores que publicaram artigos no BOLEMA formam um grupo que, apesar de estudarem e se debruçarem sobre um mesmo campo - a FPEM -, apresentam metodologias e concepções diferentes ao fazer pesquisa, tratando de peculiaridades ainda mais específicas dentro do campo, a partir da circulação intra e intercoletiva de ideias.

Ainda que assinalemos diferentes categorias no coletivo da FPEM, tratando de peculiaridades cada vez mais específicas dentro do campo, precisamos evidenciar a circulação de ideias existente entre essas categorias, que permeiam a Formação Inicial, a Formação Continuada e a Formação Contínua e o Desenvolvimento Profissional pela grande proximidade dos temas.

Assim, precisamos deixar claro que essas novas categorias estão implícitas na circulação intra e intercoletiva de ideias existente na Formação Inicial, na Formação Continuada e na Formação Contínua e no Desenvolvimento Profissional, as quais vão se modificando com a organização do campo. Afinal, "com as transformações [...] surgiram novos problemas e novos domínios do saber, de modo que, na verdade, nada está encerrado" (FLECK, 2010, p. 60).

Entendemos que os pesquisadores vinculados às categorias mais específicas, se compartilharem referenciais teóricos e práticas de pesquisa comuns no enfrentamento de um problema, podem vir a formar um coletivo de pensamento ${ }^{11}$ (FLECK, 2010). Delizoicov (2002) afirma que o coletivo de pensamento possui linguagem estilizada e códigos fechados, compartilhados apenas pelos iniciados, constituindo um círculo esotérico. Porém, o círculo exotérico se estabelece ao redor, formado pelos não iniciados cujo discurso é mais simplificado.

Os pesquisadores que produzem conhecimento científico, como é o caso dos autores e coautores dos artigos publicados no BOLEMA, por exemplo, pertencem ao que Fleck (2010) denomina de círculo esotérico, pois produzem conhecimento que será utilizado por outros

\footnotetext{
${ }^{11}$ Um estilo de pensamento é o que une os pesquisadores de um mesmo grupo, ou seja, quando compartilham um problema, referencial teórico e práticas comuns formam um coletivo de pensamento (FLECK, 2010).
} 
indivíduos, pesquisadores ou não, pertencentes ao que esse autor denomina de círculo exotérico $^{12}$.

Por fim, entendemos ser necessário e produtivo compreender como funciona a produção e a socialização do conhecimento em diversos campos do saber, no nosso caso da FPEM. Afinal, é importante refletir acerca do crescimento do número de programas de pósgraduação, de pesquisadores, de pesquisas, e como esse aumento contribui na solução de problemas e desafios.

Além disso, nosso trabalho permite compreender a estrutura do campo, quanto ao funcionamento dos seus processos, na tentativa de uma otimização, diagnosticando os núcleos existentes e os pesquisadores vinculados, para que possam se comunicar, evitando o processo de produção e socialização de um mesmo tema de forma isolada, o que não contribui para o desenvolvimento dos estudos do campo. Como enfatizado por Fiorentini et al. (2016, p.38), estudos desse tipo podem "contribuir para caracterizar e configurar melhor este campo de estudo", já que "essa modalidade de estudo ainda continua desarticulada e sem identidade própria”.

\section{Referências}

ANDRÉ, M. Formação de professores: a constituição de um campo de estudos. Educação, Porto Alegre, v. 33, n. 3, p. 174-181, set./dez. 2010.

BALANCIERI, R. et al. A análise de redes de colaboração científica sob as novas tecnologias de informação e comunicação: um estudo na plataforma lattes. Ciência da Informação, Brasília, v. 34, n. 1, p. 64-77, jan./abr. 2005.

BRASIL. Ministério da Educação e do Desporto. Mapeamento de educação matemática no Brasil 1995: Pesquisas, estudos, trabalhos técnico-científicos por subárea temática. 2. ed. Brasília: MEC, 1997. 201 p. Disponível em: <http://www.publicacoes.inep.gov.br/portal/download/356>. Acesso em 24 abr. 2016.

CECCO, B. L. Formação de professores que ensinam matemática: a circulação intra e intercoletiva de ideias nas redes configuradas no Bolema (1985-2015). 2016. 162f. Dissertação (Mestrado em Educação) - Universidade Comunitária da Região de Chapecó, Chapecó, 2016.

DANTE, L. R. [Editorial]. Boletim de educação matemática (BOLEMA), Rio Claro, v. 1, n. 1, p. 1, inverno de 1985.

DELIZOICOV, N. C. O movimento do sangue no corpo humano: história e ensino. 2002. $271 \mathrm{f}$. Tese (Doutorado em Educação) - Universidade Federal de Santa Catarina, Florianópolis, 2002.

\footnotetext{
${ }^{12}$ Fleck (2010) propõe que, ao redor de qualquer estrutura formal de um estilo de pensamento, existem círculos esotéricos e círculos exotéricos. Derivado do grego, eso significa interior, dentro, e exotérico deriva da raiz grega exo e significa exterior, fora. Desse modo, o círculo esotérico é formado por um número pequeno de indivíduos (especialistas) que tem o domínio sob determinado saber científico, e o círculo exotérico é formado por um número maior de participantes que não são especialistas na área.
} 
DINIZ-PEREIRA, J. E. A construção do campo da pesquisa sobre formação de professores. Revista da FAEEBA - Educação e Contemporaneidade, Salvador, v. 22, n. 40, p. 145-154, jul./dez. 2013.

FIORENTINI, D. Rumos da pesquisa brasileira em educação matemática: o caso da produção científica em cursos de pós-graduação. 1994. 425f. Tese (Doutorado em Educação) - Faculdade de Educação, Universidade Estadual de Campinas, Campinas, 1994.

FIORENTINI, D. et al. Formação de professores que ensinam matemática: um balanço de 25 anos da pesquisa brasileira. Educação em Revista, Belo Horizonte, n. 36, p. 137-160, dez. 2002.

FIORENTINI, D. et al. O professor que ensina matemática como campo de estudo: concepção do projeto de pesquisa. In: FIORENTINI, D.; PASSOS, C. L. B.; LIMA, R. C. R. (Org.). Mapeamento da pesquisa acadêmica brasileira sobre o professor que ensina matemática: período $2001-2012$. Campinas, SP: FE/UNICAMP, 2016. p. 17 - 42. E-Book. ISBN 978-85-7713-198-3. Disponível em: $<$ https://www.fe.unicamp.br/pf-fe/pf/subportais/biblioteca/fev-2017/e-book-mapeamento-pesquisapem.pdf>. Acesso em: 20 mar. 2017.

FLECK, L. Gênese e desenvolvimento de um fato científico. Tradução de Georg Otte e Mariana Camilo de Oliveira. 1 . ed. Belo Horizonte: Fabrefactum, 2010. 224 p. (Ciência, tecnologia e sociedade).

GABARDO, A. C. Análise de redes sociais: uma visão computacional. 1. ed. São Paulo: Novatec, 2015. $143 \mathrm{p}$.

GATTI, B.; BARRETO, E.; ANDRÉ, M. Políticas docentes no Brasil: um estado da arte. 1. ed. Brasília: UNESCO, 2011. 300 p.

LIMA, M. Y. Redes de co-autoria científica no programa de pós-graduação em geociências da UFRGS. 2009. 72f. Dissertação (Mestrado em Sociologia) - Universidade Federal do Rio Grande do Sul, Porto Alegre, 2009.

MELO, M. Três décadas em educação matemática na Unicamp: um estudo histórico a partir de teses e dissertações. 2006. 273f. Dissertação (Mestrado em Educação) - Faculdade de Educação, Universidade Estadual de Campinas, Campinas, 2006.

MINAYO, M. C. S. O desafio da pesquisa social. In: MINAYO, M. C. S.; DESLANDES, S. F.; GOMES, R. (Org.). Pesquisa social: teoria, método e criatividade. Petrópolis, RJ: Vozes, 2013. p. 930 .

PASSOS, C. et al. Desenvolvimento profissional do professor que ensina matemática: uma metaanálise de estudos brasileiros. Quadrante, Lisboa, v. 15, n. 1 e 2, p. 193-219, 2006.

PASSOS, M. O professor de matemática e sua formação: análise de três décadas da produção bibliográfica em periódicos na área de educação matemática no Brasil. 2009. 328f. Tese (Doutorado em Educação para a Ciência) - Universidade Estadual Paulista "Júlio de Mesquita Filho", Bauru, 2009.

SILVA, A. et al. Análise de redes sociais como metodologia de apoio para a discussão da interdisciplinaridade na ciência da informação. Ciência da Informação, Brasília, v. 35, n. 1, p. 72-93, jan./abr. 2006. 